\title{
Mobile Learning for Engineering Education Reform
}

\author{
Ataollah Zarei ${ }^{*}$, Khairiyah Mohd. Yusofa, Mohd Fadzil Dauda, Dayang Hjh. Tiawa Awang Hj. Hamid ${ }^{b}$ \\ ${ }^{a}$ Center of Engineering Education, University Teknologi Malaysia, 81310 UTM Johor Bahru, Johor, Malaysia \\ ${ }^{b}$ Sports Innovation Technology Centre, University Teknologi Malaysia, 81310 UTM Johor Bahru, Johor, Malaysia \\ *Corresponding author: zataollah2@live.utm.my
}

\begin{abstract}
Due to the numerous challenges facing engineering education, it should be reformed especially in engineering curricula, teaching methods and teachers' preparation. Regarding the mobile learning innovations and lack of research about its capabilities for facilitating engineering education reform, this paper aims to investigate and synthesize mobile learning potentials to support the reforming process by reviewing existing studies. The reviewed papers were analyzed using theme analysis method. Providing more opportunities to achieve professional skills and improving personal, authentic and collaborative learning activities, enhancing the quality, accessibility and acceptability of learning resources are the main benefits of mobile learning for engineering education.
\end{abstract}

Keywords: Educational technology; engineering education; mobile learning

(C) 2017 Penerbit UTM Press. All rights reserved

\subsection{INTRODUCTION}

A number of major challenges faced by Engineering Education necessitate it's reform. These include declining interest in studying engineering among high school students, low professional skills such as communication skills, critical, analytical and creative thinking among engineering graduates, improving teaching and learning theories and educational technologies, shifting program accreditation focus from documentation to outcome-based, decreasing traditional engineering jobs (Felder, 2012).

Based on the cognitive/social constructivist education paradigm, Felder (Felder, 2012) asserted that engineering curricula, teaching methods and instructors' preparation approach should be reformed to solve or reduce challenges in engineering education. Effective use of educational technologies is one of his key recommendations for facilitating engineering education reform. Due to the huge potential of mobile learning innovation to facilitate engineering education reform, providing a conceptual framework to organize and describe mobile learning potentials, help the researchers to have a big picture from this innovation for directing their researches to improve effective use of mobile learning for engineering education in their context. Furthermore, it helps the practitioners to provide general policies, strategies, or professional methods to use existing mobile learning facilities and experiences effectively in their institute or organization. Furthermore, it helps the practitioners to provide general policies, strategies, or professional methods to use existing mobile learning facilities and experiences effectively in their institute or organization.

Regarding the mentioned reasons, the main objective of this paper is synthesizing mobile learning potentials for facilitating engineering education reform through proposing a conceptual framework. To achieve this objective, the research papers about engineering education reform and mobile learning applications for engineering education were reviewed and analyzed through theme analysis method. This method enabled researchers to reveal domains and their relationships together (Onwuegbuzie et al., 2012; Creswell, 2013).

In this paper we discuss mobile learning definitions and its importance at first. Next, we propose a framework to elaborate on the roles which mobile learning can play to facilitate engineering education reforming based on Felder's recommendations (Felder, 2012) and the framework comprising characteristics of m-learning experiences which was proposed by Kearney, Schuck (Kearney et al., 2012) .

\subsection{AN OVERVIEW OF MOBILE LEARNING}

There are attempts to define mobile learning based on the novelty or the functionality of the device. Some researchers define it simply as "learning through mobile devices" (Creswell, 2013). However, as discussed by Traxler (Kearney et al., 2012), if mobile learning is defined based on technology, it could fall into the trap of becoming obsolete.

The Kearney, Schuck (Onwuegbuzie et al., 2012), suggested a pedagogical framework for mobile learning based on Traxler's approach to mobile learning (Baharom, 2013)

. From their perspective, three characteristics particular to mobile learning experiences are: personalization, authenticity, and collaboration without any time-space limitation. In his framework, personalization means providing selectable, intentional and customized learning experiences aligned with motivational and socio-cultural theories for learning. Authenticity means learning experiences that are practical 
and related to the contexts that are meaningful or valuable to the learner, and collaboration refers to the high level of multi-modal social interactivity and resource-sharing that is facilitated via mobile devices.

There are several reasons for using mobile learning for engineering education. These are investigated in the following sub-sections.

Smartphones and Tablet Capabilities

Mobile devices have significant capacity for learning, derived from mobile device technical specifications and capabilities. Some mobile phones' features and capabilities relevant to mobile learning are: memory, processor, shape \& design, applications, screen features (color, resolution, size, stylus, touch), microphone, camera (still or motion), light weight and portable, $3 \mathrm{G} / 4 \mathrm{G}$ internet access, and a range of sensors (Traxier, 2009).

Regarding these capabilities, mobile learning has many potential benefits for higher education (Traxier, 2007). Exploring and synthesizing mobile learning benefits and applications is a continuous activity undertaken by mobile learning researchers and experts based on their approach, needs, context, and continuous improvement in mobile devices and application's capabilities. Mobile learning benefits for engineering education are elaborated in the next section.

\section{Migration from Desktop to Mobile}

The global pattern of web access and using learning materials such as videos is changing from desktop to mobile. According to ComScore reports, in the U.S., the time spent on mobile apps exceeded desktop web access in Jan 2014 (ADL, 2014), while in Germany, mobile video users grew by $215 \%$ whilst online video via desktop PC or laptop users grew only 1.5\% (Gikas \& Grant, 2013). Also, according to YouTube statistics, 50\% of its global watch time comes from mobile devices like smart phones and tablets (comScore, 2014). Therefore, engineering education practitioners should consider mobile learning more, because students are already using their mobile devices extensively.

\section{New Generation of Engineering Students}

One of the main problems with the traditional teaching method is its incompatibility with engineering students' learning styles. They are mostly visual, sensing and active or reactive but teaching methods are usually verbal and teacher-centered in which students are usually passive (comScore, 2013; Youtube Statistics, 2015; Patron, 1997). However, this incompatibility is not limited to the mentioned factors. Research studies have more recently provided information about learning styles and the characteristics of the new generation of engineering students. According to Redecker, Ala-Mutka (Felder \& Silverman, 1988), this generation are characterised and thus entitled as the New Millennium Learners (NML), Net generation, Y generation and so on. They are different from previous generation, thus to improve teaching quality, instructors should consider these characteristics in their teaching styles. The researchers mentioned NML are continuously connected with their peers and always online (Mulop, 2012; Redecker et al., 2009). Also, they are impatient and need instant access to the learning resources, feedback and reward (Creswell, 2013; Oblinger et al., 2005; Pedro, 2005). Furthermore, their tendency to use multimedia learning materials and environments has been stressed in many research studies. Redecker, Ala-Mutka (Felder \& Silverman, 1988) claimed that NML cognitive patterns are non-linear, less textual, less structured, multimodal, visual, and use dynamic representations, with users more discontinuous, distracted, cognitively overloaded and distracted. Mobile learning can provide a lot of learning opportunities for engineering students which are more compatible with their learning styles and needs.

\subsection{ENGINEERING EDUCATION REFORM AND MOBILE LEARNING}

Mobile learning capabilities to facilitate engineering education reform can be modeled as Figure 1. Improving learning activities and learning resources are its main benefits. Furthermore, new engineering curricula aims can be more achievable through proper use of mobile learning innovation. These capabilities are explained below.

Engineering Curricula

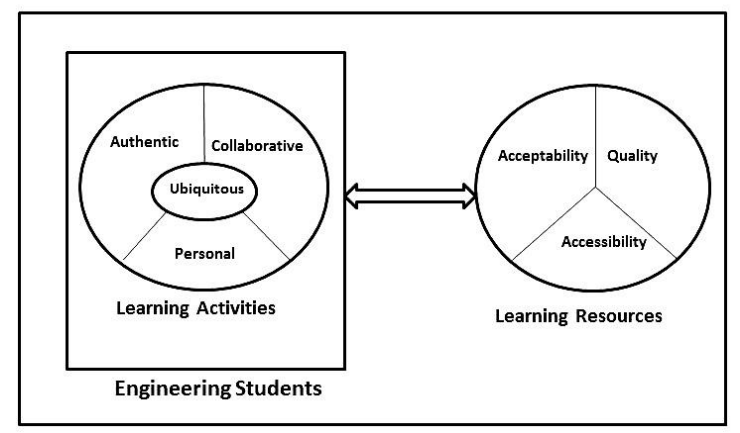

Figure 1 Framework comprising mobile learning benefits for engineering education 


\section{Reforming Curricula and Mobile Learning Potentials}

Felder (Felder, 2012), asserted that the engineering curricula should be project or problem oriented. Further, professional skills relevant to engineers such as critical thinking, communication skills and creativity are as important as content, and achieving these skills should be considered in the engineering curricula. He mentioned project and problem based learning methods are proper ways to help students attain knowledge and skills concurrently.

Although professional skills are different, supporting methods for improving these skills are partially similar. For example, problems and solutions posing, immediate access to relevant data and, information, or multimedia learning materials, reflection and peer discussion all help students to improve their critical, analytical and creative thinking, problem formulating and solving, communication and teamworking skills (Baird \& Fisher, 2005). Mobile learning provides a unique opportunities to support problem or project based learning and help engineering students to achieve professional skills.

Mobile learning can facilitate engineering students' critical and analytical thinking through project-based learning. Critical thinking is defined as "involving the ability to explore a problem, question, or situation; integrate all the available information about it; arrive a solution or hypothesis; and justify one's position" (Richard, 1998). Smartphones facilities can support engineering students through different ways when engaged in these activities to elaborate a problem or project critically. For example, regarding the importance of critical thinking for civil engineers, instructors often give assignments to students which require critical and analytical thinking. To support the students while engaging in their projects or problems in various situations, some researchers proposed a location-aware mobile app to deliver contextual knowledge to the students. The mobile app displays sub-locations including related text, images and videos on the map, given when they arrive at a pre-specified location. These materials are designed to support students in expanding their perspectives while developing their ideas or evaluating an artifact or building critically. This mobile app helps students to keep their concentration while doing outdoor project-based learning activities (Yusof et al., 2014).

Furthermore, mobile learning can provide a unique opportunity to improve engineering students' digital communication skills. According to the Oxford Dictionary, 'communication skills' means the ability to convey or share ideas and feelings effectively. It is clear that digital communication skill is as important as face to face communication skill for engineering students and graduates, and mobile learning facilities provide a lot of opportunity for all types of digital communication and the capacity to improve these abilities among students (Warnick, 1994; Alnuaim, 2014). For example, smartphones can provide ubiquitous support for students to visualize an idea, concept, procedure, problem or solution, make multimedia materials and share them, receive feedback, discuss or reflect on the others' posts to attract and convince an expert or non-expert audience.

Mobile learning can also facilitate engineering students' creative activities in classroom or lab sessions. Richards (McLester, 2007) suggested several activities such as generating ideas using tools for representations and thoughts, and playing with ideas to inspire creativity when students are faced by engineering problems. Since new ideas usually come spontaneously, mobile apps can support and enhance the creative thinking process through different ways. Apps permit students to capture, save and share the situation for further elaboration. Regarding these facilities, Terkowsky, Haertel (Gardner \& Willey; 2011) proposed a conceptual framework for a mobilebased individual learning environment combined with an e-portfolio support system to provide and facilitate creative lab learning for engineering programs.

\section{Reforming Teaching Methods and Mobile Learning Activities}

According to Felder (Felder, 2012), engineering instructors should use student-centered teaching methods which are more compatible with engineering student's learning styles. In this approach, the role of teacher is providing learning opportunities through proper design of learning activities. As Kearney, Schuck (Onwuegbuzie et al., 2012) mentioned, one of the main benefits of mobile learning is its capabilities to facilitate personal, authentic and collaborative learning activities ubiquitously. These activities are supported by a lot of learning theories under the constructivist learning umbrella. For each benefit, some experienced mobile learning innovations for engineering education are explained below.

Personalizing learning activities: Mobile learning can provide a lot of ways for engineering students to arrange their activities based on their needs, interests and possibilities. Mobile-based assessment and feedback, as a teaching and learning strategy, helps students to master the theories, manage their learning progress, or as a learning activity driver, increasing their higher order thinking skills. For example, multimedia technology and design students reported that a daily mobile-based quiz application can help them to the revise the theories related to their courses, keeps track their progress and advises how to improve through immediate feedback (Andreatos, 2012). In another study, some researchers used a mobile-based quiz to assess students' awareness of risk controlling and provide immediate feedback to ensure students are safe while visiting a learning experience (Terkowsky et al., 2014).

Authentic learning support: Mobile learning can enhance learning by contextualizing learning activities and assessment. For example, to increase students' engagement in their context and enhance their awareness of environmental and sustainability issues, researchers (Garaj, 2010) developed a smartphone application for learning biodiversity, entitled GreenHat Mobile. This application explores and alarms students about learning opportunities based on their location. To drive learning activity and to support a problembased learning strategy, students were first asked to answer multiple-choice questions about each location. Then, students received multiple expert videos about issues surrounding the argument. Also, students can capture their observations and post in on the shared map, discussing with each other about each locations highlighted on the map. The study results showed this application increased students' motivation. The students noted that the smartphone based application immersed them in the environment comparing to the desktop based application version. Another important benefit of this mobile application is increasing effectiveness of using educational material databases like contextualizing engineering pathway digital libraries.

Collaborative learning support: Mobile learning helps students to construct their knowledge cooperatively in different ways. Social media tools are strong tools to support engineering students for cooperative knowledge construction, especially when combined with problem-based learning and mobile learning (Moore et al., 2011). Comparative studies reveal that these tools can be more powerful for engineering education when used via smartphones rather than by desktop. For example, when computer science students used their smartphones in discussion situations, they engaged more in sharing knowledge, reflective thinking, and other social knowledge 
construction activities. Furthermore, the experimental group who used smartphones performed better than the control group who used desktops in terms of cooperation and diversity in constructing knowledge (Ryokai, 2012). Cooperative knowledge construction tools are not limited to well-known social media tools. Specific mobile apps can also support engineering students to construct their knowledge together- for example, a mobile app used for preparing and updating a dictionary of subject-related terms and definitions, which was used cooperatively by multimedia technology and design students (Andeatos, 2012). Luis, Mellado (Luis et al., 2014), provided a mobile app to help maritime students to annotate ideas, concepts and other notes on a virtual shared mental map through their smartphones.

\section{Mobile Learning Capabilities for Improving Learning Resources}

Engineering students should be supported by a diverse range learning resources which can covers students' learning needs and compatible to their different learning styles and speed. Books, teachers, peers, digital contents, labs and real field are the most important learning resources for engineering education. The quality, accessibility and acceptability of these resources can be improved through mobile learning facilities.

Accessibility: Time, space, cost and security are among the main barriers to access engineering learning resources. These limitations can be reduced or solved via mobile learning. For example, the cost of executing a bending test on a 9-meter long reinforced concrete beam can reach up to 15,000 USD (Lan et al., 2012). Furthermore, in some cases, it is impossible to provide real experience to help students understand concepts, procedures, and challenges in real situations, which are needed to achieve the course objectives. For example, it is impossible to make real experience about deep excavation for geotechnical engineering students (Luis et al., 2013) . Virtual labs can reduce or solve these problems via multimedia and simulation techniques. Smartphones can not only run multimedia and simulation learning materials ubiquitously, but also unique facilities such as augmented reality, which can provide extraordinary learning opportunities. For example, Luis, Mellado (Luis et al., 2014) used mobile augmented reality for chemistry practices such as investigating viscosity and density, to teach these concepts to maritime students. To explain related concepts, video contents were used to measure, manipulate or process 3D models of devices and objects. Students can use and manipulate these virtual viscometers via their smartphones and tablets instead of real ones, which can be very expensive and fragile.

Quality: Learning resources should meet engineering students learning styles who are usually visual and sensing learners. Also these resources should provide enough opportunities for active, reflective, sequential and global learners (Felder, 2012). Mobile learning facilitates and supports different student-centered teaching methods such as multimedia instruction, active and cooperative methods such as project-based learning, and cooperative problem based learning. Also, mobile learning can provide learning experiences for engineering students which are very difficult or impossible in real situations. In this sub-section, mobile learning innovations for improving the quality of course books and engineering instructors as two important learning resources are explained.

Supporting course books: Mobile multimedia instruction is an effective way to deliver teaching and learning engineering courses because it can offer multimedia learning materials ubiquitously ( Andreatos et al., 2013; Terkowsky et al., 2014; Garaj et al., 2010; Cadoni et al., 2008; Yuen \& Naidu, 2007). Some researchers (Cotton \& Barnes, 2013) prepared mobile multimedia learning materials in combination with project-based learning for teaching and learning industrial electronics subject. More than 900 industrial engineering students successfully used these materials over 3 years. It is noteworthy that mobile-based multimedia instruction is more effective than desktop-based multimedia instruction when combined with simultaneous course book reading. One study revealed that by adding QR codes to computer network course book and using a smartphone to watch related multimedia animation while reading the book, students' retention become better than using the book and watching multimedia animation by laptop or PC (Yuen \& Naidu, 2007). They noted that this method increased students' motivation to spend more time on course materials.

Teaching and teachers' supports: Mobile devices can support and improve teaching activities in the class. For example, some researchers developed a smartphone-based Student Response System (SRS) to support initial or formative assessment in class or through distance learning by facilitating questionnaire generation. Using a simple interface, teachers control on answering and voting produced immediate results and arrange their teaching based on the results in the class (Ozcelik and Acarturk, 2011). Feedback is also an important part of the assessment process, and can help students and teachers to carry out their responsibilities more effective. Smart phones can facilitate generation and distribution of teacher's audio feedback and/or student peer feedback. According to (Hassan et al., 2013), the effectiveness of teachers' feedback can be enhanced by audio feedback.

Engineering teachers need continuous supports to improve their teaching methods and engineering education reform requires prepared instructors which are usually neglected (Felder, 2012). Based on the adult education principles, engineering faculty members normally learn better if they find the subject matter has tangible applications and effects in their professional lives. Furthermore, they should be supported to learn based on their personal pace, time and space. They also like to share and discuss their experiences during learning sessions (Stav et al., 2009). Mobile learning provides a unique facility for engineering faculty members to receive information and knowledge, capture their idea and experiences, which they can share and discuss based on their needs, time and space. Therefore, mobile learning should be considered as a strong facilitator to prepare educators. Research studies show mobile learning effectiveness for teacher education in other fields (Nortcliffe \& Middleton, 2011).

Acceptability: Students' motivation is crucial for learning and teaching engineering courses (Nortcliffe \& Middleton, 2011) and educational resources especially ones that are selectable by the students should be attractive. In other words, the learning resources should useful for the students and cover their actual needs, easy to use by the students and motivate students to start and continue to use them (Baran, 2014; Fraile-Ardanuy et al., 2009). By increasing students' motivation, their cognitive engagement will be enhanced (Davis, 1989). Mobile learning can increase students' motivation in different ways. It can attract students' attention by visualization (Yuen et al., 2007, Fraile-Ardanuy et al., 2009), encourage relationships between knowledge and practice ( Luis et al., 2013; Fraile-Ardanuy et al., 2009), increase students' self-confidence (Fraile-Ardanuy et al., 2009; Keller, 2008), increase students' satisfaction (Garaj, 2010; FraileArdanuy et al., 2009) and help students to employ volitional strategies by providing ubiquitous access to learning materials (FraileArdanuy et al., 2009). 


\subsection{CONCLUSION}

Engineering education should be reformed, especially in engineering curricula, teaching methods and instructors' preparation approach, to cover existing and future challenges. Due to the mobile devices capabilities, learners' migration from desktop to mobile, and the new generation of engineering students' learning styles, mobile learning can provide extensive opportunity to facilitate this reform. It can facilitate engineering curricula reforming process in which professional skills are as important as fundamental skills through supporting students' learning activities and provide better opportunities for them to improve their professional skills such as critical and analytical thinking, communication skills and creativity. Also, it can improve teaching methods by facilitating personalizing learning activities, and supporting authentic and collaborative learning. Furthermore, it provides more accessible and acceptable learning materials for the students. Finally, it can provide a lot of learning opportunities and methods for supporting engineering instructors.

\section{References}

ADL, Mobile Learning Handbook. Retrived from adlnet.gov: http://sites.google.com/a/adlnet.gov/mobile-learning-guide/basics, n.d.

Alnuaim, A., P. Caleb-Solly, and C. Perry. (2014). A Mobile Location-Based Situated Learning Framework for Supporting Critical Thinking: A Requirements Analysis Study, in Digital Systems for Open Access to Formal and Informal Learning. Springer, . 139-158.

Andreatos, A. (2012). Educating the 21st Century's Engineers and IT Professionals. New Media Communication Skills for Engineers and IT Professionals: TransNational and Trans-Cultural Demands: Trans-National and Trans-Cultural Demands, 132.

Baird, D.E. and M. Fisher (2005). Neomillennial User Experience Design Strategies: Utilizing Social Networking Media To Support" Always On" Learning Styles. Journal Of Educational Technology Systems, 34(1),. 5-32.

Baharom, S. (2013). Designing mobile Learning Activities In The Malaysian HE Context : A Social Constructivist Approach, in School of Business. University of Salford.

Baran, E. (2014). A Review of Research on Mobile Learning in Teacher Education. Journal of Educational Technology \& Society, 17(4), 17-32.

Cadoni, E., L. Botturi, and D. Forni (2008). The TEMAS Multimedia Learning Objects for Civil Engineers. TechTrends. $52(5), 17$.

comScore. (2013). Major Mobile Milestones in May: Apps Now Drive Half of All Time Spent on Digital. 2014 02/02/2015]; Available from: http://www.comscore.com/Insights/Blog/Major-Mobile-Milestones-in-May-Apps-Now-Drive-Half-of-All-Time-Spent-on-Digital\#imageview/0/.

comScore. (2015). Growth of Video in Germany: PC and Mobile. 02/02/2015]; Available from: http://www.comscore.com/Insights/Data-Mine/Growth-of-Video-inGermany-PC-and-Mobile.

Cotton, I. and M. Barnes (2013). The power engineering guide: A mobile application for education and wider engagement. International Journal of Electrical Engineering Education, 50(3), 247-255.

Creswell, J.W. (2013). Research Design: Qualitative, Quantitative, And Mixed Methods Approaches. Sage Publications.

Davis, F.D. (1989). Perceived Usefulness, Perceived Ease Of Use, And User Acceptance Of Information Technology. MIS Quarterly, 319-340.

Douglas, E.P. (2012). Defining and measuring critical thinking in engineering. Procedia-Social and Behavioral Sciences, 56. $153-159$.

Felder, R.M. (2012). Engineering Education: a Tale of two paradigms. Shaking the Foundations of Geoengineering Education, Bryan McCabe (Editor), Marina Pantazidou (Editor), Declan Phillips (Editor), 9-14

Felder, R.M. and L.K. Silverman (1988) Learning and Teaching Styles In Engineering Education. Engineering Education. 78(7),. 674-681.

Fraile-Ardanuy, J., Garcia-Gutierrez, P., Perez, J. I., and Fraile-Mora, J. J. (2009) Improving Understanding Of Single Phase Transformer Behaviour Through A Multimedia Tool. International Journal of Electrical Engineering Education, 46(1),. 74-89.

Garaj, V. (2010). m-Learning in the Education of Multimedia Technologists and Designers at the University Level: A User Requirements Study. Ieee Transactions on Learning Technologies, 3(1), 24-32

Gardner, A. and K. Willey. Peer Feedback-What Are Students Telling Each Other? in Proceedings of the 39th SEFI Annual Conference. 2011.

Gikas, J. and M.M. Grant (2013). Mobile Computing Devices In Higher Education: Student Perspectives On Learning With Cellphones, Smartphones \& Social Media. The Internet and Higher Education, 19,. 18-26.

Hassan, H., Martinez-Rubio, J.-M., Perles, A., Capella, J.-V., Dominguez, C., and Albaladejo, J. (2013). Smartphone-Based Industrial Informatics Projects and Laboratories. Ieee Transactions on Industrial Informatics, 9(1), 557-566.

Jarvis, P. (1995). Adult and continuing education: Theory and Practice. Psychology Press.

Kearney, M., Schuck, S., Burden, K., and Aubusson, P. (2012). Viewing Mobile Learning From A Pedagogical Perspective. Research In Learning Technology, 20, 1, 1-17. doi: 10.3402/rlt. v20i0/14406. Note: open access journal.

Keller, J.M. (2008). First principles of motivation to learn and e3- learning. Distance Education, 29(2), $175-185$.

Luis, C.E.M., R.C. Mellado, and B.A. Díaz (2013). PBL Methodologies with Embedded Augmented Reality in Higher Maritime Education: Augmented Project Definitions for Chemistry Practices. Procedia Computer Science, 25, 402-405.

Luis, M., Efren, C., Gutierrez, J. M., and González Marrero, A. M. (2014). Using Mobile Devices And Internet Technologies In Problem-Based Learning: Design of a suitable Active And Collaborative Learning Environment In Engineering Education. in Frontiers in Education Conference (FIE), IEEE. 2014. IEEE.

Lan, Y. F., Tsai, P. W., Yang, S. H., and Hung, C. L. (2012). Comparing the Social Knowledge Construction Behavioral Patterns Of Problem-Based Online Asynchronous Discussion In E/M-Learning Environments. Computers and Education, 59(4), 1122-1135.

McLester, S. (2007) Technology literacy and the MySpace generation. Technology and Learning. 27(8), 17-22.

Moore, G., R. Kerr, and R. Hadgraft (2011) Self-Guided Field Trips For Students Of Environments. European Journal of Engineering Education, 36(2), 107-118.

Mulop, N. (2012) The Effectiveness Of Learning Thermodynamics Through Multimedia Courseware Based On Visualization And Constructivism. Universiti Teknologi Malaysia.

Mulop, N., K. Mohd Yusof, and Z. Tasir (2014). The Improvement Of Confidence Level Of Students Learning Thermodynamics Through A Multimedia Courseware. In Global Engineering Education Conference (EDUCON), IEEE. 2014

Nortcliffe, A. and A. Middleton (2011). Smartphone Feedback: Using An Iphone To Improve The Distribution Of Audio Feedback. International Journal of Electrical Engineering Education, 48(3), 280-293.

Oblinger, D., J.L. Oblinger, and J.K. Lippincott (2005). Educating The Net Generation: < p > Boulder, Colo.: EDUCAUSE, c2005. $<$ p $><$ p $>1$ v.(various pagings): illustrations. $</ \mathrm{p}>$

Onwuegbuzie, A.J., N.L. Leech, and K.M. Collins (2012). Qualitative Analysis Techniques For The Review Of The Literature. The qualitative report. 17(28): p. 1.

Ozcelik, E. and C. Acarturk (2011). Reducing the Spatial Distance Between Printed And Online Information Sources By Means Of Mobile Technology Enhances Learning: Using 2D Barcodes. Computers and Education, 57(3), 2077-2085.

Patron, F. (1997). Conceptual Understanding of Thermodynamics:A Study of Undergraduate and Graduate Students. Purdue University.

Pedró, F. (2006). The New Millennium Learners: Challenging Our Views On ICT And Learning. Inter-American Development Bank.

Redecker, C., Ala-Mutka, K., Bacigalupo, M., Ferrari, A., and Punie, Y. (2009). Learning 2.0: The impact of Web 2.0 innovations on education and training in Europe. Final Report. European Commission-Joint Research Center-Institute for Porspective Technological Studies, Seville.

Richards, L.G. (1998) Stimulating creativity: teaching engineers to be innovators. in Frontiers in Education Conference, 1998. FIE'98. 28th Annual. 1998. IEEE.

Ryokai, K., A.M. Agogino, and L. Oehlberg (2012.) Mobile Learning with the Engineering Pathway Digital Library. International Journal of Engineering Education 28(5), 1119-1126 
Sorden, S.D. (2012) The Cognitive Theory of Multimedia Learning, in The Handbook of Educational Theories, B.J. Irby, G. Brown, and S. Jackson, Editors. Information Age Publishing, Incorporated.

Stav, J., Nielsen, K., Hansen-Nygård, G., and Thorseth, T. (2010). Experiences obtained with integration of student response systems for ipod touch and iphone into elearning environments. Electronic Journal of e-Learning. 8(2): p. 179-190.

Terkowsky, C., Haertel, T., Bielski, E., and May, D. (2014) Bringing the inquiring mind back into the labs a conceptual framework to foster the creative attitude in higher engineering education. in Global Engineering Education Conference (EDUCON). IEEE.

Traxler, J. (2009). Current State of Mobile Learning. Transforming The Delivery Of Education And Training, M. Ally, Editor. 2009, : AU Press, Athabasca University.: Edmonton.

Traxler, J. (2007). Defining, Discussing and Evaluating Mobile Learning: The moving finger writes and having writ. The International Review of Research in Open and Distance Learning. 8(2).

YouTube Statistics. Mobile and Devices (2015). [02/02/2015]; Available from: https://www.youtube.com/yt/press/en-GB/statistics.html.

Yuen, S.T.S. and S. Naidu (2007). Using multimedia to close the gap between theory and practice in engineering education. International Journal of Engineering Education,. 23(3): p. 536-544

Yusof, K. M., Hassan, S. A. H. S., Jamaludin, M. Z., and Harun, N. F. (2012). Cooperative problem-based learning (CPBL): Framework for integrating cooperative learning and problem-based learning. Procedia-Social and Behavioral Sciences, 2012. 56: p. 223-232.

Warnick, B. and E.S. Inch (1994). Critical thinking and communication: The use of reason in argument. 1994: Macmillan College. 